\title{
Does Ethanol Play a Pro-0xidant Role during Oxidative Stress in the Liver?
}

\author{
Patience 0. Obih ${ }^{1,2}$, Joseph S. Soblosky ${ }^{1,2}$, Barry J. Potter ${ }^{3}$ \\ ${ }^{1}$ College of Pharmacy, Xavier University of Louisiana, New Orleans, USA \\ ${ }^{2}$ The Alcohol Research Center, LSU Health, New Orleans, USA \\ ${ }^{3}$ The Department of Physiology at LSU Health, New Orleans, USA \\ Email:poobih@xula.edu
}

Received 29 May 2015; accepted 2 August 2015; published 5 August 2015

Copyright (C) 2015 by authors and Scientific Research Publishing Inc.

This work is licensed under the Creative Commons Attribution International License (CC BY). http://creativecommons.org/licenses/by/4.0/

(c) †) Open Access

\begin{abstract}
Oxidative stress has been implicated in the pathophysiology of liver injury during xenobiotic and alcohol metabolism, ischemia/reperfusion injury. In this study we examined if ethanol acted as a pro-oxidant making cells become more sensitive to tert-butylhydroperoxide (tBH) killing. Cell viability was determined in a rat hepatoma cell line (FTO2B) and rat primary hepatocytes in culture in the presence or absence of ethanol pretreatment. To elucidate the contribution of labile iron, deferoxamine (DF, an iron chelator) or lipid free radicals, $\mathrm{N}, \mathrm{N}$-diphenyl-p-phenylenediamine (DPPD, a lipid scavenger) were added to the ethanol tBH co-treatment. The levels of glutathione (GSH) and glutathione disulfide (GSSG) in the hepatocytes were also measured. Ethanol treatment (both pretreatment and co-treatment during the 3-hr tBH exposure) increased cell killing dramatically in both FTO2B cells and primary rat hepatocytes. Both DF and DPPD decreased ethanol-enhanced tBH cell killing in hepatocytes. These results demonstrated that co-treatment of FTO2B cells and primary rat hepatocytes with ethanol and tBH increased cell killing. The GSH level was dramatically reduced while GSSG level rose. Both DFP and DPPD reversed or protected the cells from this insult, indicating that ethanol was a pro-oxidant.
\end{abstract}

\section{Keywords}

Ethanol, Liver, Hepatocytes, FTO2B Cells, t-Butyl Hydroperoxide

\section{Introduction}

One of the major targets of continued alcohol abuse is the liver, which is also the major site of its metabolism. The cause of liver damage due to ethanol appears to be multifactorial, involving enzyme induction, toxic metabolites, glutathione depletion and alterations to the labile iron pool. Oxidative stress has also been implicated in 
the pathophysiology of this liver injury and is similar to that seen during xenobiotic metabolism, ischemia/reperfusion injury, and activated phagocytic cell attack [1]. Drug hepatotoxicity, allograph dysfunction following liver transplantation, and liver injury by endotoxin mediated activation of Kupffer cells have also all been associated with oxidative stress [2] [3]. Molecular mechanisms by which oxidants trigger the cascade leading to cell death are, however, not fully understood. Normally, liver cells contain high levels of low-molecular-weight antioxidants and antioxidant enzymes, including vitamin E, reduced glutathione, ascorbic acid, superoxide dismutase and catalase to protect the cells from reactive oxygen species (ROS) and other free radicals. However, in oxidative injury, these antioxidant defense mechanisms become overwhelmed, leading to oxidative stress and ultimately to cell death via either necrotic or apoptotic pathways.

Free radicals and reactive oxygen species (ROS) are continuously produced in vivo. These hyper-reactive moieties include the superoxide anion, the hydroxyl radicals, hydrogen peroxide singlet oxygen and a variety of reactive nitrogen species (RNS) besides subsequent downstream free radicals formed by them (including the 1hydoxyethyl radical) and lipid peroxidation products. Cells are known to produce ROS either as a defense mechanism against invading pathogens, or as a byproduct of enzymatic activity [4]. A major source of ROS is from the mitochondrial electron transport chain. ROS may be produced by other mechanisms. NADH (nicotinic adenine dinucleotide, reduced) oxidase, present in phagocytic cells, is activated by activation of the immune/inflammatory system, and produces large quantities of superoxide anion and hydrogen peroxide. Activated neutrophils also release myeloperoxidase from granules, converting hydrogen peroxide and chloride ions to hypochlorous acid, a powerful oxidizing and chlorinating agent that can react with numerous biological targets to cause cellular injury [5] [6]. Cells have basal level of ROS production that is normally countered by the cellular anti-oxidant defense system. However, disturbances to this homeostatic system that cause an increase in ROS generation, a cellular redox shift, or decrease in the anti-oxidant defense systems lead to diseases resulting from the cellular and tissue injury. It has been suggested that this is one of the mechanisms involved in type 2 diabetes [7] and has also been implicated in the pathogenesis of atherosclerosis and hypertension [8] [9]. While ethanol is known to affect almost every biochemical system in the liver, ethanol abuse is associated with considerable oxidative stress [10]-[12]. There are varieties of mechanisms by which ethanol can affect free radical formation, the liver and other organs of the body, and cause alcoholic liver disease (ALD). These pathways also include the generation of hydroxylethanol free radicals. Some workers have stated that the signaling pathways affected by direct or indirect alcohol exposure range from oxidative stress mechanisms, metabolism related effects, inflammation and apoptosis [13]. Some groups have focused on CYP2E1, part of the microsomal ethanol oxidation system (MEOS), which is inducible by continued alcohol intake. This system has been shown to readily generate ROS, particularly hydrogen peroxide, superoxide and hydroxyl radicals, in the presence of ethanol [14] [15]. It has been shown that alcohol increases lipid peroxidation and also modifies proteins. For instance, many investigators have shown that administration of antioxidants, or agents that reduce the levels of free iron, can prevent or treat the deleterious effect of alcohol [12] [16] [17]. Oxidative stress that occurs in the liver affects not only the resident liver cells but also circulating immune cells such as dendritic cells, neutrophils, and bone marrow derived stem cells that migrate to the liver, cause inflammatory responses, and propagate alcoholic liver injury [13].

In this study we have investigated the direct effect of ethanol by exposing rat hepatocytes in primary culture to ethanol with or without the addition of the organic peroxide, tertiary-butyl hydroperoxide (tBH), to simulate oxidative stress. Comparison has also been made to a rat hepatoma cell line which metabolizes ethanol by the alcohol dehydrogenase pathway, and possesses low constitutive levels of CYP2E1. Exposure of isolated hepatocytes to organic peroxides, such as tertiary-butyl hydroperoxide, results in rapid oxidation of cellular lipids, and a rapid loss of cell viability [18]-[20]. The aim of this study is therefore to examine if ethanol acts as a pro-oxidant, causing increased sensitivity of hepatocytes to $\mathrm{tBH}$, and by extension to predisposition to liver disease.

\section{Experimental Methods}

\subsection{Cell Culture}

Two types of liver cell were used in these experiments: a cultured rat hepatoma cell line, FTO2B, and freshly isolated rat hepatocytes in primary culture.

Hepatocytes were isolated from 175 gm male Sprague Dawley rats (Harlan, Indianapolis, IN) using a modification of the in situ collagenase perfusion technique [3] [21]. The cells thus obtained were purified further by 
Percoll gradient centrifugation to remove non parenchymal cells. The cells were cultured overnight at $37^{\circ} \mathrm{C}$ in an atmosphere of $5 \% \mathrm{CO}_{2} 95 \%$ air in Williams medium E containing $1 \mu \mathrm{M}$ insulin, $2 \mathrm{mM}$ glutamine, $10^{5} \mathrm{U} / \mathrm{l}$ penicillin, $100 \mathrm{mg} / \mathrm{l}$ streptomycin, and $10 \%$ low endotoxin fetal calf serum (heat inactivated) in 12 -well plates, coated with type I collagen, at a density of 200,000 cells per well. The cells were treated as indicated in the text for $3 \mathrm{hr}$. at $37^{\circ} \mathrm{C}$. At the end of treatment the cell viability was determined by assaying for lactate dehydrogenase (LDH) in the culture supernatant and in the lysed cells. LDH levels were measured spectrophotometrically using a commercially available kit (Sigma-Aldrich, St. Louis, MO).

\subsection{Cell Culture of FT02B Cells}

The rat hepatoma cell line, FTO2B was cultured at $37^{\circ} \mathrm{C}$ in $5 \% \mathrm{CO}_{2}$ atmosphere in Dulbecco's modified Eagle's medium/Ham's F12 medium (1:1) supplemented with 10\% bovine serum, $2 \mathrm{mM}$ glutamine, 50 I.U./ml penicillin-streptomycin, and $0.2 \%$ sodium bicarbonate. FtO2B cells $\left(2 \times 10^{5} / \mathrm{ml}\right)$ were plated in 12 well plates and allowed to adhere overnight prior to an experiment. Following this pre-incubation, the cells were treated with graded doses of $\mathrm{tBH}$ and incubated for 3 hours. Cell viability was determined by assaying the culture supernatant for lactate dehydrogenase (LDH). Lysis of the cells with Triton X-100 was used as a measure of total or $100 \%$ killing.

\subsection{Treatment}

Initially, the dose response curves were determined following a 3 hour incubation of tBH with hepatocytes or FTO2B cells. Subsequently to these determinations, sub lethal doses of t-BH $\left(<\mathrm{LD}_{50}\right)$ were used throughout the study. After overnight equilibration, FTO2B cells or hepatocytes were incubated in the presence or absence of $100 \mathrm{mM}$ ethanol for a further $24 \mathrm{hr}$; after which they were challenged with a sub lethal dose of tBH for three hours. In separate experiments, cells with or without ethanol pretreatment were incubated with $200 \mu \mathrm{M} \mathrm{tBH}$ in the presence or absence of $4 \mu \mathrm{M}$ DPPD, or $20 \mathrm{mM}$ desferrioxamine for $3 \mathrm{hr}$. At the end of treatment, cell viability was determined by assaying the culture supernatant for lactate dehydrogenase

\subsection{Measuement of Glutathione in Hepatocytes}

In order to examine the mechanism of action of ethanol in the presence of $\mathrm{tBH}$, this study was extended to measure the levels of glutathione and GSSG in the primary rat hepatocytes. The cells were pretreated with or without ethanol for $24 \mathrm{hr}$. followed by $30 \mathrm{~min}$. incubation with $200 \mu \mathrm{M} \mathrm{tBH}$ with or without ethanol. Glutathione was assayed by a standard spectrophotometric method [8] [22].

\subsection{Materials}

Penicillin-streptomycin and glutamine were purchased from Cellgro (Herndon, VA, USA). Culture media was from Gibco Laboratories (Rockville, MD, USA). N,N'-diphenyl-1,4-phenylene diamine (DPPD) was purchased from Aldrich (Milwaukee, WI, USA).Reduced glutathione (GSH) and oxidized glutathione (GSSG) were purchased from Borhringer (Indianapolis, IN).

\section{Statistical Analysis}

All the results are expressed as mean \pm SEM values. The Tukey t-test was applied to data from the FTO2B cells. Values were considered significant at $\mathrm{p}<0.05$.

\section{Results}

As may be seen in Figure 1 there was a graded dose response curve of tBH killing of hepatocytes. Doses between 0 and $200 \mu \mathrm{M}$ tBH had no effect on the viability of the hepatocytes whereas $300 \mu \mathrm{M}$ produced approximately $50 \%$ cell killing. Higher doses of this peroxide resulted in almost complete death of the cultured liver cells. The rat liver cell line (FTO2B cells) were more resistant to killing by tBH; a $50 \%$ loss of viability was not observed until the concentration had been raised to between 600 and $800 \mu \mathrm{M}$ tBH (the data not shown, but the percentage killing may be seen in Figure 3(a)). The addition of $100 \mathrm{mM}$ ethanol to $200 \mu \mathrm{M} \mathrm{tBH}$, which by itself produced little change in cell viability, resulted in a dramatic loss of cell viability after 30 - 60 minutes incubation, as seen in Figure 2. This did not occur when the cells were incubated with $100 \mathrm{mM}$ ethanol in the absence 


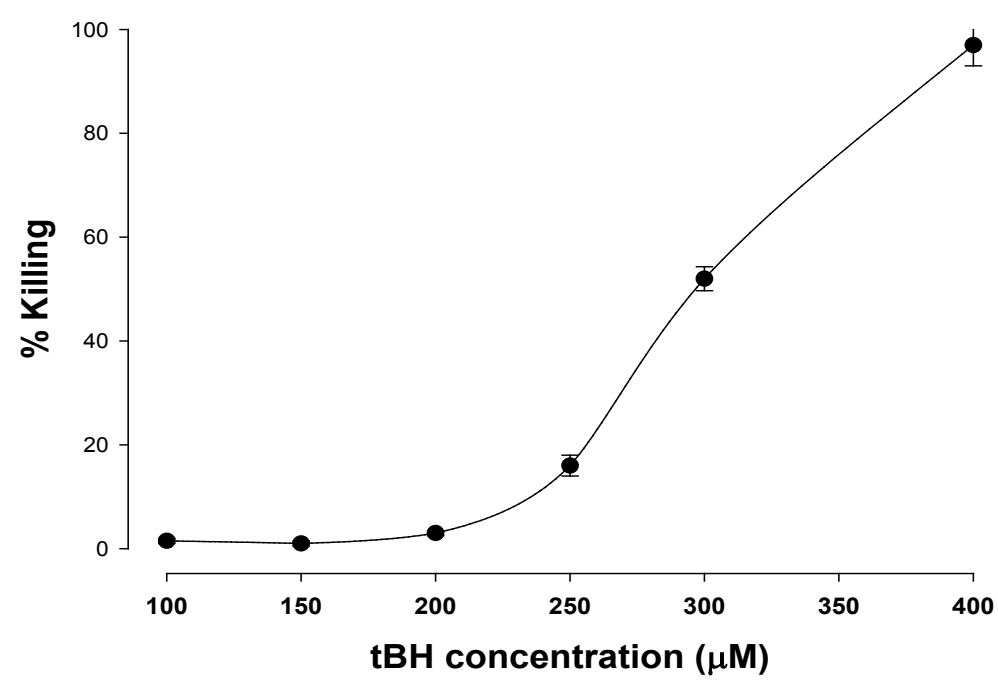

Figure 1. Dose response curve for the killing of rat hepatocytes in primary culture by tertiary-butyl hydroperoxide (tBH). Freshly isolated hepatocytes were cultured on collagen overnight and the media changed prior to experimentation. The cells were then treated with various concentrations of $\mathrm{tBH}$, dissolved in the medium and incubated at $37^{\circ} \mathrm{C}$ for 180 minutes. Cell killing was assessed as the percentage of LDH leakage in this time compared to the values for hepatocytes lysed with triton X-100.

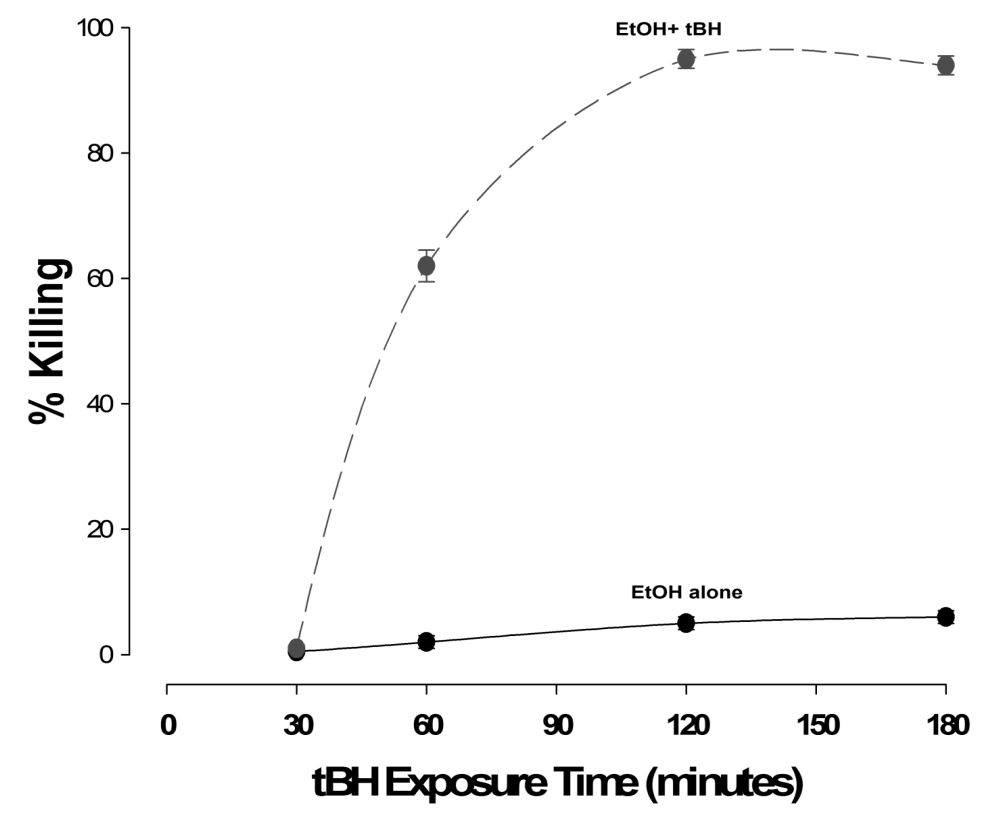

Figure 2. Time curves for the effect of $200 \mu \mathrm{M}$ tertiary-butyl hydroperoxide (tBH) on cultured rat hepatocytes in the presence or absence of $100 \mathrm{mM}$ ethanol. Freshly isolated rat hepatocytes were cultured overnight and the media changed prior to experimentation. At time zero, $200 \mu \mathrm{M} \mathrm{tBH}$ was added, together with media alone (solid line) or media containing $100 \mathrm{mM}$ ethanol (dashed line). At present time intervals, medium was aspirated and the LDH and cellular protein content quantitated. The values were then expressed in terms of cultured cells lysed by the addition of triton X-100.

of tBH (the curves for ethanol were very similar to those observed for low doses of $\mathrm{tBH}$, i.e. $\leq 200 \mu \mathrm{M}-$ data not shown). 
In order to ascertain the contribution of ethanol and its metabolism on the cytotoxic effects of tBH, cells were incubated overnight (24 hours) in the presence or absence of $100 \mathrm{mM}$ ethanol and then for 3 hours with two different concentrations of tBH, again in the presence or absence of ethanol. To compensate for difference engendered by ethanol alone, cells cultured in ethanol for 24 hours were also assayed in media without ethanol when tBH was added and vice versa. As may be seen in Figure 3(a), $600 \mu \mathrm{M}$ tBH resulted in the killing of only 10\% of the FTO2B cells, whereas $800 \mu \mathrm{M}$ killed almost 60\%. Culturing FTO2B cells in ethanol alone resulted in approximately four-fold increase in killing by $\mathrm{tBH}$, at the lower concentration and complete killing of all the cells at the higher concentration. No significant difference was observed between the ethanol/ethanol + tBH groups and media/ethanol + tBH groups suggesting that it was the presence of ethanol together with tBH that was responsible for the cytotoxic activity, rather than the long-term effects of ethanol alone. Similar results were also seen with the cells cultured in the medium without ethanol. When a similar system was employed with the rat hepatocytes in primary culture, lower concentrations of tBH were used. $200 \mu \mathrm{m}$ tBH produced similar killing in medium alone (ca 10\%). However, $300 \mu \mathrm{M}$ tBH resulted in approximately $70 \%$ killing, suggesting that these cells were more sensitive to oxidative stress than the FTO2B cells. Apart from this difference in sensitivity, the cells responded similarly to the FTO2B cells in terms of the presence or absence of ethanol together with tBH, as may be seen in Figure 3(b).

In order to test whether free/labile iron was associated with the cellular killing, such as its utilization in the Fenton/Haber-Weiss reactions to produce hydroxyl radicals or donate free electrons to free radical-mediated reactions, cells were incubated with $\mathrm{tBH}$ in the presence or absence of $20 \mathrm{mM}$ desferrioxamine. In the experiments shown in Figure 4(a), desferrioxamine reduced cell killing by tBH in hepatocytes to virtually zero. In every other case, cytotoxic activity was reduced to or below control values. Similar results were obtained with FTO2B cells, as may be seen in Figure 4(b).

Since $\mathrm{tBH}$, a known generator of oxidative stress seems to be involved in lipid oxidation apoptotic/necrotic pathways of cell death, experiments were carried out in the presence or absence of an antioxidant, N,N'-diphenyl-phenylene diamine (DPPD). As may be seen in Figure 5(a) and Figure 5(b), the addition of $200 \mu \mathrm{mM}$ DPPD resulted in effective prevention of cell killing, suggesting that lipid peroxidation is involved in the cytotoxic activity of tBH and ethanol.

To ascertain whether tBH altered the oxidative status of the cells, glutathione was also measured in cultured hepatocytes. The level of GSH was high in control cells (media alone: $2750 \mathrm{ng} /$ well) and ethanol-treated cells (ethanol alone: $2500 \mathrm{ng} / \mathrm{well}$ ) while oxidized glutathione levels were low (200 for media and $100 \mathrm{ng} / \mathrm{well}$ for ethanol-treated cells). However, in the presence of tBH and ethanol, the level of GSSG increased (1750 ng/well) while GSH level decreased ( $400 \mathrm{ng} / \mathrm{well}$ ), as may be seen in Figure 6. These results suggest that glutathione levels can be maintained in the presence of a single oxidant stressor, such as tBH, but not in the presence of an additional factor, such as the presence of ethanol.

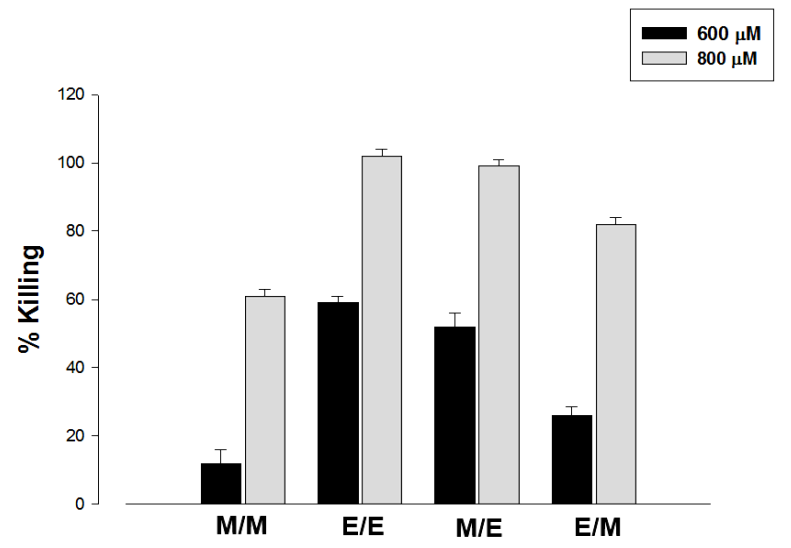

(a)

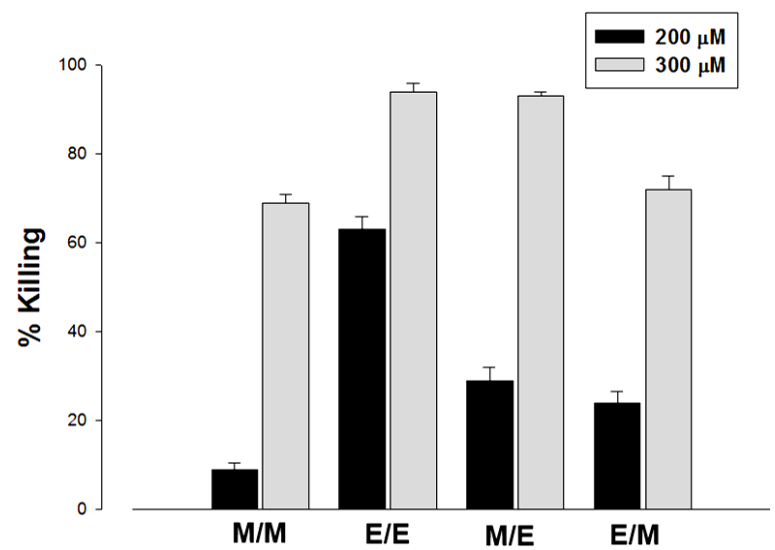

(b)

Figure 3. Effects of ethanol on cell killing by tertiary-butyl hydroperoxide (tBH). (a) FTO2B cells: $600 \mu \mathrm{M}$ tBH-black bars; $800 \mu \mathrm{M} \mathrm{tBH}$ - grey bars; (b) Rat hepatocytes in primary culture:200 $\mu \mathrm{M}$ tBH-black bars; $300 \mu \mathrm{M} \mathrm{tBH}$-grey bars. M/M $=24-\mathrm{hr}$ culture in media alone followed by $3-\mathrm{hr}$ incubation in media and $\mathrm{tBH}$. E/E $=24$-hr culture in ethanol $(100 \mathrm{mM})$ alone followed by 3-hr incubation in ethanol and $\mathrm{tBH} . \mathrm{M} / \mathrm{E}=24-\mathrm{hr}$ culture in media alone followed by 3-hr incubation in ethanol $(100 \mathrm{mM})$ and $\mathrm{tBH} . \mathrm{E} / \mathrm{M}=24-\mathrm{hr}$ culture in ethanol $(100 \mathrm{mM})$ alone followed by 3 -hr incubation in media and $\mathrm{tBH}$. 


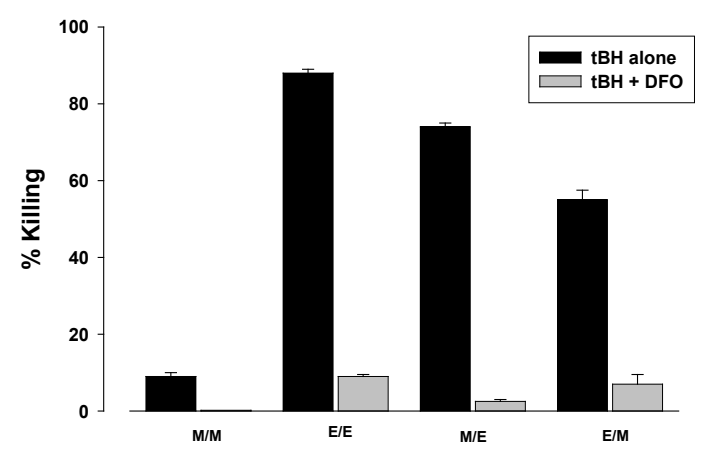

(a)

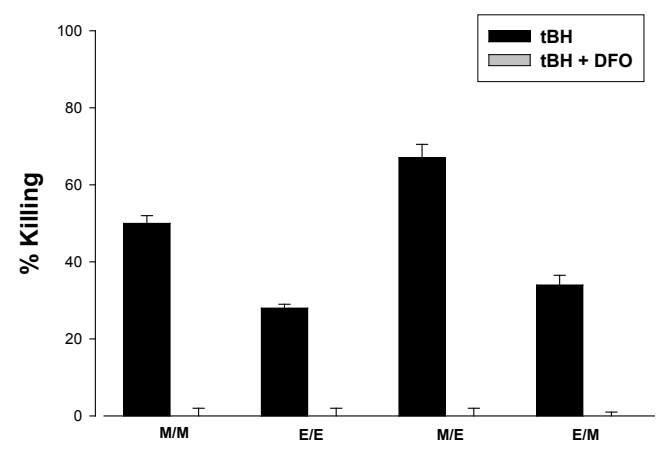

(b)

Figure 4. Effects of the addition of desferrioxamine (DFO) on the cell killing by tertiary-butyl hydroperoxide (tBH). (a) FTO2B cells: $600 \mu \mathrm{M}$ tBH—black bars; $800 \mu \mathrm{M} \mathrm{tBH}$ - grey bars; (b) Rat hepatocytes in primary culture:200 $\mu \mathrm{M} \mathrm{tBH}-$ black bars; $300 \mu \mathrm{M}$ tBH-grey bars. $\mathrm{M} / \mathrm{M}=24-\mathrm{hr}$ culture in media alone followed by 3 -hr incubation in media and $\mathrm{tBH}+/-$ DFO.E/E $=24-\mathrm{hr}$ culture in ethanol followed by $3-\mathrm{hr}$ incubation in ethanol and $\mathrm{tBH}+/-\mathrm{DFO} . \mathrm{M} / \mathrm{E}=24 \mathrm{hr}$ culture in media followed by 3-hr incubation in ethanol and $\mathrm{tBH}+/-\mathrm{DFO} . \mathrm{E} / \mathrm{M}=24-\mathrm{hr}$ culture in ethanol followed by 3-hr incubation in media + /- DFO.

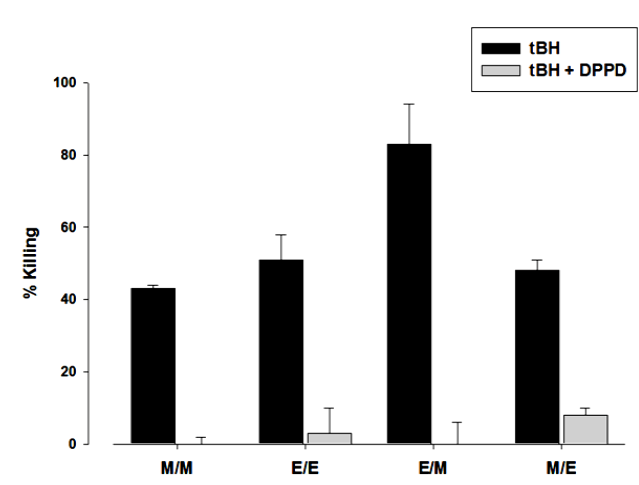

(a)

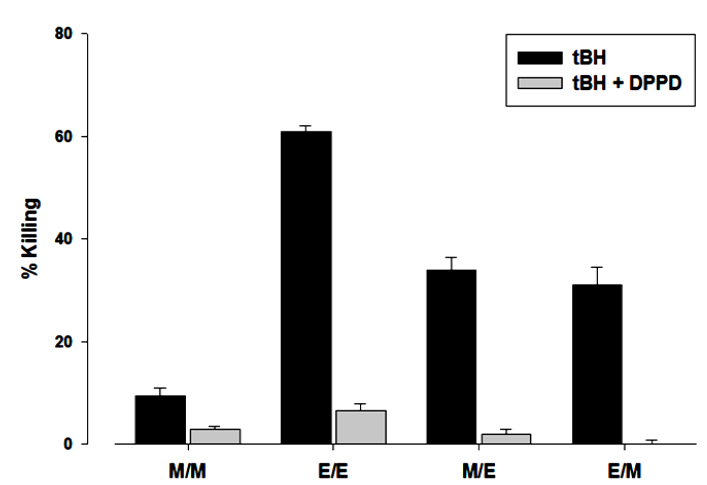

(b)

Figure 5. Effects of the addition of N,N-diphenyl-p-phenylenediamine (DPPD) on the cell killing by tertiary-butyl hydroperoxide (tBH). (a) FTO2B cells: $600 \mu \mathrm{M} \mathrm{tBH}$-black bars; $800 \mu \mathrm{M} \mathrm{tBH}$-grey bars; (b) Rat hepatocytes in primary culture: $\mathrm{M} / \mathrm{M}=24-\mathrm{hr}$ culture in media alone followed by $3-\mathrm{hr}$ incubation in media and $\mathrm{tBH}+/-\mathrm{DPPD}$. E/E $=24-\mathrm{hr}$ culture in ethanol followed by $3-\mathrm{hr}$ incubation in ethanol and $\mathrm{tBH}+/-$ DPPD. $\mathrm{M} / \mathrm{E}=24-\mathrm{hr}$ culture in media followed by 3-hr incubation in ethanol and $\mathrm{tBH}+/-$ DPPD.

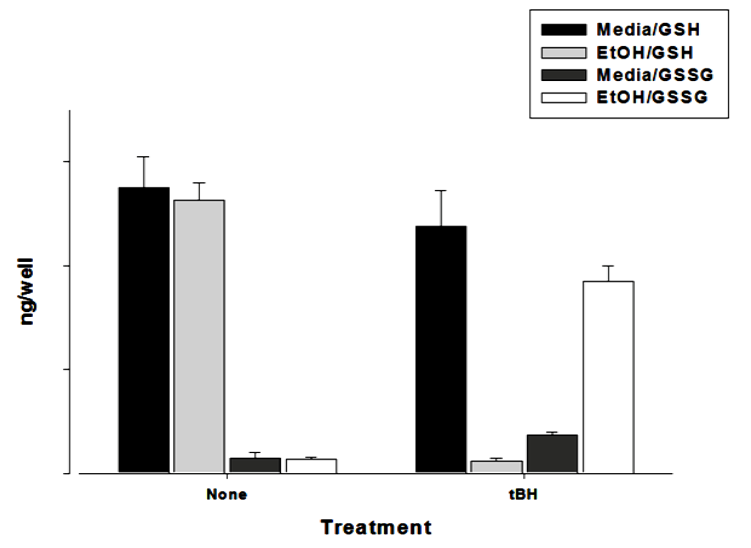

Figure 6. Effects of $200 \mu \mathrm{M}$ tBH exposure on GSH and GSSG levels in cultured hepatocytes. Rat hepatocytes were cultured in the presence of medium containing $100 \mathrm{mM}$ ethanol or medium alone for 24 hours at $37^{\circ} \mathrm{C}$. The medium was then removed and replaced with medium containing $100 \mathrm{mM}$ ethanol or medium alone and $\mathrm{tBH}$ and incubated for a further 180 minutes. GSH and GSSG levels were then determined as described in the methods section. 


\section{Discussion}

Response to alcohol has been shown as a factor contributing to immense health hazard. Habitual consumption of alcohol produces a spectrum of hepatic pathology, ranging from simple steatosis (fatty liver) on one extreme, to cirrhosis on the opposite end of the spectrum. Steatohepatitis, a liver disease characterized by hepatic steatosis, inflammation, and increased hepatocyte death, is usually an intermediate stage between simple fatty liver and cirrhosis. Steatosis is a very common result of chronic alcohol ingestion, occurring in many, if not most, human beings and experimental animals that consume alcohol daily. In contrast, cirrhosis is a relatively rare outcome of chronic alcohol ingestion. Cell damage sets in gradually before the whole liver is engulfed. Our study showed no significant cell killing by LDH assay with the $24 \mathrm{hr}$ ethanol pretreatment controls in both hepatocytes and FTO2B cells. Tert-butyl hydroperoxide is a toxin that has been frequently employed as a model to study the mechanism of irreversible cell injury resulting from an acute oxidative stress [23]. We found that neither 0.2 $\mathrm{mM}$ of tBH nor $100 \mathrm{mM}$ Ethanol alone was significantly toxic to the cells. However, when hepatocytes were treated at the same time with Ethanol and $0.2 \mathrm{mM} \mathrm{tBH}$, cell killing increased dramatically. In effect, the presence of Ethanol converted the $0.2 \mathrm{mM}$ tBH from being without effect to a toxic cell insult. This was also observed when Ethanol was only added to $\mathrm{tBH}$ without $24 \mathrm{hr}$ Ethanol pretreatment. Both deferoxamine (DF, an iron chelator) and N,N-diphenyl-p-phenlylenediamine (DPPD, a lipid radical scavenger) were able to reverse or protect the cells from this insult. In other words, the inclusion of DPPD in the incubation medium prevented cell death. Some researchers have shown that at a concentration of $250 \mu \mathrm{M}$ tert-buthyl hydroperoxide, $\alpha$-tocopheroldeficient hepatoytes incubated with DPPD were completely protected against cell killing, whereas cells not incubated with DPPD were not [24]. Exposure of isolated rat hepatocytes to allyl alcohol, diethyl maleate and bromoisovalerylurea induce lipid peroxidation, depletion of free protein thiols to about $50 \%$ of the control value and cell death [25]. Other studies have also shown that membrane stability may play an important part in anti-oxidant protections, since taurine has been shown to be protective against tBH administration [26].

Glutathione is a critical antioxidant. Our study indicates that its level is normal in the dose for Ethanol and tBH used separately. However, when hepatocytes were exposed to both Ethanol and tBH, the level of GSH became dramatically reduced while GSSG level rose. Other workers have shown that mitochondrial thiols undergo oxidative modification in rats chronically fed alcohol for at least one month [27] and this mitochondrial oxidative stress may also be one of the longer-term damaging consequences of alcohol intoxication. This mitochondrial dysfunction may also lead to increased free radical production following disruption of the electron chain. There has been a controversy whether alcohol liver disease is due to malnutrition or direct hepatotoxicity of ethanol. Some researchers have shown that alcohol liver disease develops as a consequence of priming and sensitizing mechanisms rendered by cross-interactions of primary mechanistic factors and secondary risk factors. The critical role of hepatic macrophages has been highlighted as a priming mechanism and glutathione depletion in hepatocyte mitochondria is considered the most important sensitizing mechanism. Methionine metabolism is also considered as another contributing factor [28]. It has been shown previously that in isolated hepatocytes, tert-butyl hydroperoxide is metabolized by the glutathione peroxidase-glutathione reductase enzyme system present in the cytosolic and mitochondrial compartments. Metabolism of $t$-BH may result in a decrease in both the glutathione (GSH)/glutathione disulfide (GSSG) and NADPH/NADP ${ }^{+}$redox ratios, and in a diminished intracellular concentration of exchangeable $\mathrm{Ca}^{2+}$ depending on the concentration of $t$-BH. Some workers described a biphasic action of nitric oxide in its effects on oxidative killing of isolated cells [29]. They observed that low concentrations of nitric oxide protect against oxidative killing, while higher doses enhance killing and these two effects occur by distinct mechanisms.

There is little doubt that the labile iron pool is also involved in this oxidative stress. As well as experimental cell culture, iron accumulation is often increased in patients with alcohol-related liver disease and that this is related to an increase in hepatic transferrin receptors irrespective of non-transferrin-bound plasma iron [30]-[32]. The effects of excess iron may be far-reaching and include oxidative stress-related perturbations of the endoplasmic reticulum [33]. Evidence also suggests that P450 2E1 may be one of the co-factors causing free radical production from this compartment [20] [34]. Other radicals, such as carbon-centered radicals (1-hydroxyethyl), produced by CYP450-Fe-oxycomplexes and hydroxyl radicals from the Fenton-Haber-Weiss reaction may also increase toxicity, as shown by increases in $\mathrm{F}_{2}$-isoprostanes [35].

\section{Conclusion}

The data presented above indicate that $\mathrm{tBH}$-ethanol cell killing is associated with peroxidation of cellular lipids. 
The ability of DFP and DPPD to prevent tBH-ethanol cell killing may relate to their antioxidant action. In summary, the data observed in this work suggest that the killing of hepatocytes by tert-butylhydroperoxide and ethanol can be attributed to the peroxidation of cellular phospholipids and that free iron is probably involved in the mechanistic pathway. Liver disease is the most common medical complication of alcohol abuse; an estimated $15 \%-30 \%$ of chronic heavy drinkers eventually develop severe liver disease. Alcohol fatty liver is a reversible condition that may progress to alcoholic hepatitis and eventually to cirrhosis and liver failure [36]. Preventing excessive alcohol consumption is a major part of the solution to alcohol problem.

\section{References}

[1] Groskreutz, J.L., Bronk, S.F. and Gores, G.J. (1992) Ruthenium Red Delays the Onset of Cell Death during Oxidative Stress of Rat Hepatocytes. Gastroenterology, 102, 1030-1038.

[2] Chamulitrat, W., Carnal, J., Reed, N.M., and Spitzer. J.J. (1998) In Vivo Endotoxin Enhances Biliary Ethanol-Dependent Free Radical Generation. American Journal of Physiology-Gastrointestinal and Liver, 274, G653-G661.

[3] Potter, B.J., Blades, B., McHugh, T.A., Nunes, R.M., Beloqui, O., Slott, P.A. and Rand J.H. (1989) Effects of Endotoxin on Iron Uptake by the Hepatocytes. American Journal of Physiology, 257, G524-G531.

[4] Cross, C.E., Halliwell, B., Borish, E.T., Pryor, W.A., Ames, B.N., Saul, R.L., McCord, J.M. and Harman, D. (1987) Oxygen Radicals and Human Disease [Clinical Conference]. Annals of Internal Medicine, 107, 526-545. http://dx.doi.org/10.7326/0003-4819-107-4-526

[5] Grisham, M.B. and Yamada, T. (1992) Neutrophils, Nitrogen Oxides, and Inflammatory Bowel Disease. Annals of the New York Academy of Sciences, 664, 103-115. http://dx.doi.org/10.1111/j.1749-6632.1992.tb39753.x

[6] Alzoghaibi, M.A. (2013) Concepts of Oxidative Stress and Antioxidant Defense in Crohn's Disease. World Journal of Gastroenterology, 19, 6540-6547. http://dx.doi.org/10.3748/wjg.v19.i39.6540

[7] Ayin, A., Orhan, H., sayal, A., Ozata, M., Sahin, G. and Isimer, A. (2001) Oxidative Stress and Nitric Oxide Related Parameters in Type II Diabetes Mellitus: Effects of Glycemic Control. Clinical Biochemistry, 34, 65-70. http://dx.doi.org/10.1016/S0009-9120(00)00199-5

[8] Cathcart, M.K., McNally, A.K., Morel, D.W. and Chisolm, G.M., (1989) Superoxide Anion Participation in Human Monocyte-Mediated Oxidation of Low-Density Lipoprotein and Conversion of Low-Density Lipoprotein to a Cytotoxin. Journal of Immunology, 142, 1963-1969.

[9] Haliwell, B (1989) Free Radicals, Reactive Oxygen Species and Human Disease: A Critical Evaluation with Special Reference to Atherosclerosis. British Journal of Pathology, 70, 737-757.

[10] Cardin, R., D’Errico, A., Fiorentino, M., Ceccehtto, A. Naccarto, R. and Farinati, F. (2002) Hepatocyte Proliferation and Apoptosis in Relation to Oxidative Damage in Alcohol-Related Liver Disease. Alcohol, 37, 43-48. http://dx.doi.org/10.1093/alcalc/37.1.43

[11] Zima, T., Fialova, L., Mestek, O., Janebova, M., Crkovska, J., Malbohan, I., Tipek, S., Mikulikova, L. and Popov, P. (2001) Oxidative Stress, Metabolism of Ethanol and Alcohol-Related Diseases. Journal of Biomed Science, 8, 59-70. http://dx.doi.org/10.1007/BF02255972

[12] $\mathrm{Wu}, \mathrm{D}$. and Cederbaum, A.I. (2003) Alcohol, Oxidative Stress, and Free Radical Damage. Alcohol Research and Health, 27, 277-284.

[13] Mandrekar, P. and Ambade, A. (2012) Chapter 6: Cellular Signaling Pathways in Alcoholic Liver Disease: Trends in Alcoholic Liver Disease Research. In: Shimizu, I., Ed., Clinical and Scientific Aspects, InTech, Rijeka, 91-112.

[14] Dai, Y., Rashba-Step, J. and Cederbaum, A.I. (1993) Stable Expression of Human CYP 2E1 in HepG2 Cells: Characterization of Catalytic Activities and Production of Reactive Oxygen Intermediates. Biochemistry, 32, 6928-6937. http://dx.doi.org/10.1021/bi00078a017

[15] Rashba-Step, J., Turro, N.J. and Cederbaum, A.I. (1993) Increased NADPH- and NADH-Dependent Production of Superoxide and Hydroxyl Radical after Chronic Ethanol Treatment. Archives of Biochemistry and Biophysics, 300, 401-408. http://dx.doi.org/10.1006/abbi.1993.1054

[16] Nanji, A.A., Jokelainen, K., Tipoe, G.L., Rahemtulla, A. and Dannenberg, A.J. (2001) Dietary Saturated Fatty Acids Reverse Inflammatory and Fibrotic Changes in Rat Liver despite Continued Ethanol Administration. Journal of Pharmacology and Experimental Therapeutics, 299, 638-644.

[17] Wheeler, M.D., Kono, H., Yin, M., Rusyn, I., Froh, M., Connor, H.D., et al. (2001) Delivery of the Cu/Zn-Superoxide Dismutase Gene with Adenovirus Reduces Early Alcohol-Induced Liver Injury in Rats. Gastroenterology, 120, 12411250. http://dx.doi.org/10.1053/gast.2001.23253

[18] Bellomo, G., Jewell, S.A. and Orrenius, S. (1982) Regulation of Intracellular Calcium Compartmentation: Studies with 
Isolated Hepatocytes and t-Butyl Hydroperoxide. Proceedings of the National Academy of Sciences of the United States of America, 79, 6842-6846. http://dx.doi.org/10.1073/pnas.79.22.6842

[19] Bellomo, G., Thor, H. and Orrenius, S. (1984) Increase in Cytosolic $\mathrm{Ca}^{2+}$ Concentration during t-Butyl Hydroperoxide Metabolism by Isolated Hepatocytes Involves NADPH Oxidation and Mobilization of Intracellular $\mathrm{Ca}^{2+}$ Stores. FEBS Letters, 168, 38-42. http://dx.doi.org/10.1016/0014-5793(84)80202-1

[20] Roberto, I., Nieminen, A., Herman, B. and Lemasters, J.L. (1992) Mitochondrial and Glycolytic Dysfunction in Lethal Injury to Hepatocytes by t-Butyl Hydroperoxide: Protection by Fructose, Cyclosporin A and Trifluperazine. The Journal of Pharmacology and Experimental Therapeutics, 265, 392-400.

[21] Kim, Y.M., Bergonia, H. and Lancaster, J.R. (1995) Nitrogen Oxide-Induced Autoprotection in Isolated Rat Hepatocytes. FEBS Letters, 374, 228-232. http://dx.doi.org/10.1016/0014-5793(95)01115-U

[22] Griffith, O.W. (1980) Determination of Glutathione and Glutathione Disulfide Using Glutathione Reductase and 2-Vinylpyridine. Analytical Biochemistry, 106, 207-212. http://dx.doi.org/10.1016/0003-2697(80)90139-6

[23] Ochi, T. (1990) Effects of an Organic Hydroperoxide on the Activity of Antioxidant Enzymes in Cultured Mammalian Cells. Toxicology, 61, 229-239. http://dx.doi.org/10.1016/0300-483X(90)90173-E

[24] Masaki, N., Kyle, M.E. and Farber, J.L. (1989) Tert-Butyl Hydroperoxide Kills Cultured Hepatocytes by Peroxidizing Membrane Lipids. Archives of Biochemistry and Biophysics, 269, 390-399.

[25] Dogterom, P., Mulder, G.J. and Nagelkerke, J.F. (1989) Lipid Peroxidation-Dependent and -Independent Protein Thiol Modifications in Isolated Rat Hepatocytes: Differential Effects of Vitamin E and Disulfiram. Chemico-Biological Interactions, 71, 291-306. http://dx.doi.org/10.1016/0009-2797(89)90042-2

[26] Roy, A. and Sil, P.C. (2012) Tertiary Butyl Hydroperoxide Induced Oxidative Damage in Mice Erythrocytes: Protection by Taurine. Pathophysiology, 19, 137-148. http://dx.doi.org/10.1016/j.pathophys.2012.05.001

[27] Venkatraman, A., Landar, A., Davis, A.J., Ulasova, E., Page, G., Murphy, M.P., Darley-Usmar, V. and Bailey, S.M. (2004) Oxidative Modification of Hepatic Mitochondria Protein Thiols: Effect of Chronic Alcohol Consumption. American Journal of Physiology, 286, G521-G527. http://dx.doi.org/10.1152/ajpgi.00399.2003

[28] Tsukamoto, H. and Lu, S.C. (2001) Current Concepts in Pathogenesis of Alcoholic Liver Injury. FASEB Journal, 15, 1335-1349. http://dx.doi.org/10.1096/fj.00-0650rev

[29] Joshi, M.S., Ponthier, J.L. and Lancaster, J.R. (1999) Cellular Antioxidant and Pro-Oxidant Actions of Nitric Oxide. Free Radical Biology \& Medicine, 27, 1357-1366. http://dx.doi.org/10.1016/S0891-5849(99)00179-3

[30] Kohgo, Y., Ohtake, T., Ikuta, K., Suzuki, Y., Saito, H. and Kato, J. (2005) Iron Accumulation in Alcoholic Liver Diseases. Alcohol Clinical and Experimental Research, 29, 189S-193S. http://dx.doi.org/10.1097/01.alc.0000189274.00479.62

[31] Do, T.H.T., Gaboriau, F., Cannie, I., Batusanski, F., Ropert, M., Moirand, R., Brissot, P., Loreal, O. and Lescoat, G. (2013) Iron-Mediated Effect of Alcohol on Hepatocyte Differentiation in HepaRG Cells. Chemical and Biological Interactions, 206, 117-125. http://dx.doi.org/10.1016/j.cbi.2013.08.016

[32] Zhang, H. and Potter, B.J. (1991) The Effect of Ethanol Metabolism on Ferritin Uptake by Freshly Isolated Rat Hepatocytes: Is Acetaldehyde Responsible for This Action? Alcoholism: Clinical and Experimental Research, 16, 301-307. http://dx.doi.org/10.1111/j.1530-0277.1992.tb01381.x

[33] Tan, T.C., Crawford, D.H., Jaskowski, L.A., Subramaniam, V.N., Clouston, A.D., Craine, D.I., Bridle, K.R., Anderson, G.J. and Fletcher, L.M. (2013) Excess Iron Modulates Endoplasmic Reticulum Stress-Associated Pathways in a Mouse Model of Alcohol and High-Fat-Induced Liver Injury. Laboratory Investigation, 93, 1295-1312. http://dx.doi.org/10.1038/labinvest.2013.121

[34] Lu, Y. and Cederbaum, A.I. (2006) Cisplatin-Induced Hepatotoxicity Is Enhanced by Elevated Expression of Cytochrome P450 2E1. Toxicological Sciences, 89, 515-523.

[35] Comporti, M., Signorini, C., Leoncin, S., Gardi, C., Ciccoli, L., Giardini, A., Vecchio, D. and Arrezini, B. (2010) Ethanol-Induced Oxidative Stress: Basic Knowledge. Genes \& Nutrition, 5, 101-109. http://dx.doi.org/10.1007/s12263-009-0159-9

[36] Masters, S.B. and Trevor, A.J. (2015) Alcohols. Basic \& Clinical Pharmacology, 23, 384-395. 